\title{
BMJ Open Study protocol for a pragmatic randomised controlled trial evaluating efficacy of a smoking cessation e-`Tabac Info Service': ee-TIS trial
}

\author{
L Cambon, ${ }^{1,2}$ P Bergman, ${ }^{3}$ Al Le Faou, ${ }^{4,5}$ I Vincent, ${ }^{3}$ B Le Maitre, ${ }^{5}$ A Pasquereau, ${ }^{6}$ \\ P Arwidson, ${ }^{6}$ D Thomas, ${ }^{5,7,8} \mathrm{~F} \mathrm{Alla}^{2,3}$
}

To cite: Cambon $L$, Bergman $\mathrm{P}$, Le Faou $\mathrm{A}$, et al. Study protocol for a pragmatic randomised controlled trial evaluating efficacy of a smoking cessation e-'Tabac Info Service': ee-TIS trial. BMJ Open 2017;7:e013604. doi:10.1136/bmjopen-2016013604

- Prepublication history for this paper is available online. To view these files please visit the journal online (http://dx.doi.org/10.1136/ bmjopen-2016-013604).

Received 25 July 2016 Revised 9 January 2017 Accepted 13 January 2017

\section{CrossMark}

For numbered affiliations see end of article.

Correspondence to Dr Linda Cambon; Linda. cambon@ehesp.fr

\section{ABSTRACT}

Introduction: A French national smoking cessation service, Tabac Info Service, has been developed to provide an adapted quitline and a web and mobile application involving personalised contacts (eg, questionnaires, advice, activities, messages) to support smoking cessation. This paper presents the study protocol of the evaluation of the application (e-intervention Tabac Info Service (e-TIS)). The primary objective is to assess the efficacy of e-TIS. The secondary objectives are to (1) describe efficacy variations with regard to users' characteristics, (2) analyse mechanisms and contextual conditions of e-TIS efficacy.

Methods and analyses: The study design is a twoarm pragmatic randomised controlled trial including a process evaluation with at least 3000 participants randomised to the intervention or to the control arm (current practices). Inclusion criteria are: aged 18 years or over, current smoker, having completed the online consent forms, possessing a mobile phone with android or apple systems and using mobile applications, wanting to stop smoking sooner or later. The primary outcome is the point prevalence abstinence of 7 days at 6 months later. Data will be analysed in intention to treat (primary) and per protocol analyses. A logistic regression will be carried out to estimate an $\mathrm{OR}(95 \% \mathrm{Cl})$ for efficacy. A multivariate multilevel analysis will explore the influence on results of patients' characteristics (sex, age, education and socioprofessional levels, dependency, motivation, quit experiences) and contextual factors, conditions of use, behaviour change techniques.

Ethics and dissemination: The study protocol was reviewed by the ethical and deontological institutional review board of the French Institute for Public Health Surveillance on 18 April 2016. The findings of this study will allow us to characterise the efficacy of e-TIS and conditions of its efficacy. These findings will be disseminated through peer-reviewed articles.

Trial registration number: NCT02841683; Pre-results.

\section{Strengths and limitations of this study}

- Large national randomised trial in pragmatic conditions.

- Process analysis within the trial using Medical Research Council framework and behavioural change techniques taxonomy in order to understand mechanisms and conditions of efficacy.

\section{INTRODUCTION}

Every year, smoking causes 6.1 million deaths worldwide and an estimated 143.5 million Disability Adjusted Life Years (DALYs). ${ }^{1}$ Health risks associated with smoking depend on two factors: daily consumption ${ }^{2}$ and duration of smoking. Conversely, smoking cessation is good for health and the sooner a smoker quits, the better. ${ }^{3}{ }^{4}$ People who stop smoking by the age of 40 reduce their likelihood of dying from smoking-related diseases by over $90 \%$, and by the age of 30 the figure stands at $97 \% .^{3}$ Those who quit at 40 live 7 years longer and at 50 live 4 years longer ${ }^{4}$ compared with those who do not quit. In addition, smoking cessation does not just reduce mortality; it also brings down morbidity. ${ }^{5}$

Various types of support and treatment are available, with varying results. Best evidence examples include: individual professional counselling, ${ }^{6}$ nicotine replacement therapy (NRT), motivational interviewing, ${ }^{7}$ group behavioural therapy, ${ }^{8}$ nursing interventions, ${ }^{9}$ self-help tools ${ }^{10}$ for patients who prefer not to seek the help of a healthcare professional or call helplines, ${ }^{8}$ support via mobile phone text messaging. ${ }^{11}$ Whatever the method used, the relapse prevention model ${ }^{12}$ stresses the need to provide greater support in the so called high-risk situations. Non-pharmacological treatments must therefore be tailored to the 
patient to deal adequately with different immediate determinants (high-risk situations, coping skills in front of high-risk situations, outcome expectancies and the abstinence violation effect) and the covert antecedents (lifestyle factors, stress, denial, cravings) as these factors can contribute to relapse.

Drawing on this knowledge, the Caisse Nationale d'Assurance Maladie des Travailleurs Salariés (CNAMTS) (the French National Health Insurance Fund) and the national agency of public health (Santé Publique France -Public Health France) with the support of the French smoking cessation specialists association (Société Francophone de Tabaccologie) have come together to design, experiment and assess a new e-coaching intervention named e-intervention Tabac Info Service (e-TIS). The intervention is a mobile phone application designed to provide intensive support to smokers who are wishing to quit, including those who are not currently trying to. It is based on the effectiveness criteria of online programmes, ${ }^{12}$ psychosocial and behavioural change theories $^{13-19}$ and the expertise from Société Française de Tabacologie (SFT) members. E-TIS aims, therefore, to help smokers to progress through different stages (contemplation, intention, action) by providing tailored activities, self-reporting exercises, tips and social or psychological support, reassurance and motivational text messages. All these contacts are adapted to individual characteristics and level of progress. This article describes the protocol used to assess it. The protocol follows the recommendations of the Consolidated Standards of Reporting Trials (CONSORT) ${ }^{20}$ and Standard Protocol Items: Recommendations for Interventional Trials (SPIRIT) 2013 guidelines. ${ }^{21}$

\section{OBJECTIVES}

The primary objective is to assess the efficacy of e-TIS. The secondary objectives are to (1) describe efficacy variations with regard to users' characteristics, (2) analyse mechanisms and contextual conditions of e-TIS efficacy.

\section{METHODS AND ANALYSES \\ Rationale}

The intervention is complex and many variables influence the outcomes. To achieve the secondary objectives of the study, we have followed the recommendations of the Medical Research Council (MRC) ${ }^{22} 23$ and the Workgroup for Intervention Development and Evaluation Research (WIDER). ${ }^{24}$ In 2000, the MRC published a framework, updated in $2012^{25}$ concerning the evaluation of complex interventions. The framework stresses the need to base the intervention on a theory in order to understand which components are effective and in which conditions.

In 2007, following the 21st annual conference of the European Health Psychology Society, the WIDER issued a consensus statement which outlined that specific behavioural change intervention (BCI) reporting has to be used in conjunction with the CONSORT statement.
The philosophy is that greater clarity about the functional components of behaviour change interventions is essential to ensure that interventions are delivered to influence outcomes. The WIDER recommendations are now an established framework for identifying and describing the essential components for detailed reporting of BCIs. In line with these frameworks, our second objective is to assess the intervention's key functions, ${ }^{26}$ in other words, the environmental or intervention components that determine its efficacy. To achieve this, we will draw on the taxonomy by Michie $e t a l^{27} 28$ which has enabled us to describe the behavioural change techniques (BCTs) used in the intervention. We will also report the external environmental or social factors and consider additional individual characteristics that could influence the efficacy of the intervention.

\section{Study design}

The evaluation will be conducted as a pragmatic randomised controlled trial combined with a process analysis. The e-TIS intervention will be compared against current practices for smoking cessation as set out on a noninteractive website (ameli-sante.fr, Cnamts).

To do this, the evaluation sets out the smoking cessation treatments as recommended by the Haute Autorité de Santé (HAS); independent national scientific body with a broad remit on health and healthcare issues) and consists of two arms: the intervention arm (use of the e-TIS intervention) and a control arm (current practices).

\section{Study setting}

This pragmatic trial takes place in France on a national level. The application was launched in October 2016. The evaluation will take place between 1 January 2017 and 1 March 2017.

\section{Eligibility criteria}

Inclusion criteria are: all adult smokers, who have completed the online consent form, agreeing to participate in the study, possessing a mobile phone using apple and android system, willing to use applications, and envisaging quitting smoking (in the short, medium or long term). An inclusion questionnaire is included with the consent form to screen potential participants (smoker or not, age, sex, wish to stop smoking, smartphone use) and to identify the technical characteristics for setting up the study (eg, randomisation), such as email and phone number.

\section{Sample size}

The required sample size was calculated using a hypothesis of a $10 \%$ abstinence rate at the 6-month follow-up (similar to the rate observed in the StopAdvisor trial. ${ }^{29}$ Given a rate of $10 \%$ in the control group, a sample of 1500 subjects per group is required to show an OR of 1.5 (ie, a rate of $14 \%$ in the intervention group) with a power of $90 \%(\alpha 0.05$, bilateral test), meaning a total of 3000 persons. ${ }^{30}$ 


\section{Recruitment}

Subjects will be recruited as the e-TIS website becomes operational and over three full months (January-March 2017). The study will start in January 2017 and end in July 2018. Data will be collected over 12 months. Recruitment will be via France's national health insurance fund's website Ameli: http://www.ameli-sante.fr. Subjects will $\log$ on to the Ameli website where they see a banner for the study. If they click on the banner, they will be taken to the website of the study and will be invited to participate. Here they will find an information sheet along with a section where they can give their informed consent. The consent form contains the inclusion questionnaire. If consent is given, a confirmation email will be sent to the person (link to click on). Once the volunteers have confirmed, they will be randomised, and a second email and a text message will be sent to them. These contain a password so that they can log on to the entry questionnaire (T0) for the study. And once this questionnaire is completed, the participants will be assigned to one of the study arms. Figure 1 shows the procedure. Given that the Ameli website has an average of 1.8 million single visits per month and the prevalence of smokers in the French adult population is above $30 \%,{ }^{31}$ we could estimate that $\sim 600000$ smokers will be connected in a 3-month period. The inclusion period can be adapted to the actual number of people volunteering. Please note that during the first month of operation of e-TIS, 33000 persons downloaded this application, which is an argument for the feasibility of the inclusion process.

\section{Randomisation}

Automated randomisation will be carried out following receipt of all necessary data, and consent by the subject to participate in the study. A minimisation software package will be used to reduce of the risk of unmatched groups and will be applied to stratify participants according to sex and age using the following parameters: two treatment arms, e-TIS (E) and Ameli.fr (A) allocated $50 / 50$; stratified by sex $(\mathrm{M} / \mathrm{F})$ and by age $( \pm 45$ years old); drawn for the first 30 subjects, $5 \%$ drawn, 0.96 randomisation factor.

\section{Intervention}

Intervention arm: participants will be assigned to one of two arms before the treatment begins. Those participants assigned to the intervention arm will be exposed to the e-TIS intervention. In keeping with the precepts of the relapse prevention model, the treatment will be individually tailored to each smoker throughout, based on feedback collected along the way. The support process draws on the efficacy criteria of online programmes (frequency and intensity of contacts, short messages, interactivity, appeal, personalisation, credibility of content, share functions) and various theoretical models used in withdrawal treatments.

The intervention will primarily involve personalised interactive (push) contacts via mobile phone, website platform and tablet. These contacts are questionnaires, advice, activities and text messages. The intervention comprises 16 different activities and eight position questionnaires with different purposes. The position questionnaires are designed to help smokers to progress: A questionnaire to guide participants through the modules; a questionnaire about smoker status; a customisation questionnaire (presence of other smokers, ecigarette use, cannabis consumption, contraceptive methods, pregnancy, just gave birth, cardiovascular or respiratory diseases, previous quit attempts); a dependency questionnaire; a questionnaire about support preferences; a questionnaire about withdrawal symptoms; a
Figure 1 Recruitment procedure.

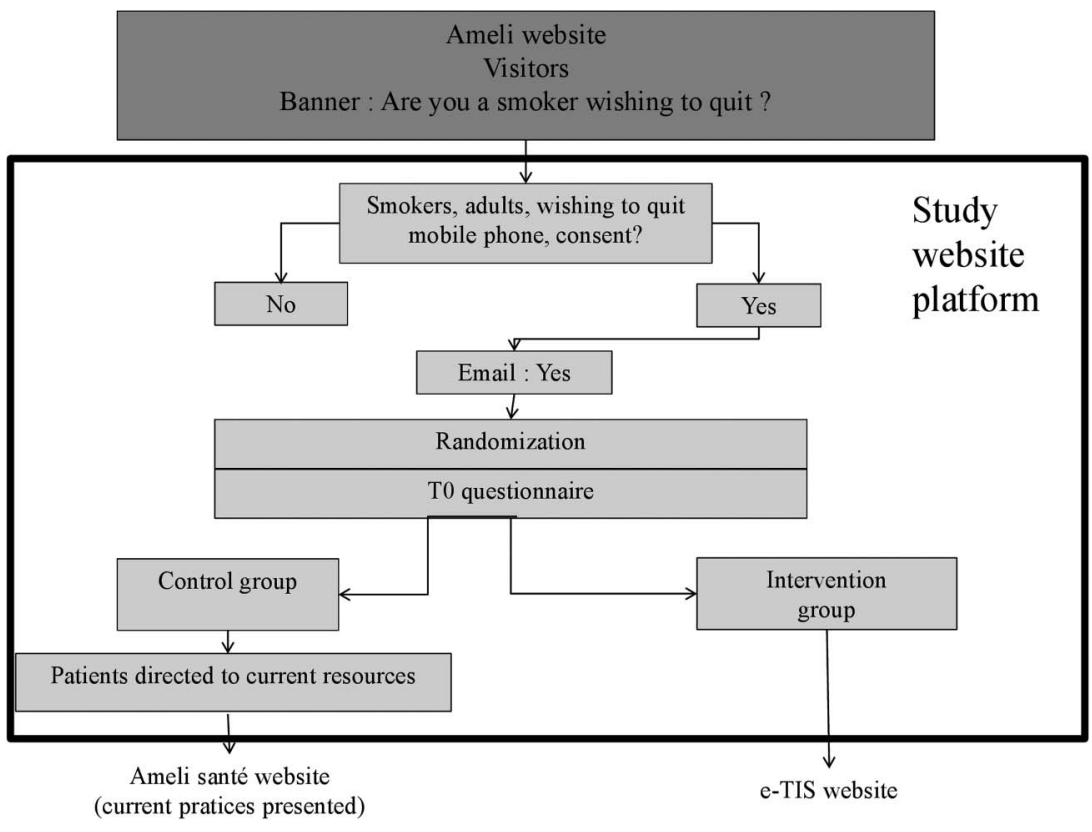


questionnaire about self-efficacy; a questionnaire about craving.

The purposes of the 16 activities are:

AC1-Decisional balance: to define and prioritise the pros and cons of quitting.

AC2-Fears and obstacles: to identify fears and obstacles associated with quitting and to obtain some information or reassurance about smoking cessation.

AC3-The cigarette log: to report daily cigarette consumption and define the cigarettes really appreciated and important and furthermore difficult to leave.

AC4-Cost of smoking: to be aware of the cost of smoking (modules 1 and 2) and the savings to be made if one quits (module 3 ).

AC5-Quit date choice: to help the smoker choose the best time to attempt quitting, and to enroll the support of others who should be aware of the quit date.

AC6-My motivations: to review the smoker's motivation to take the decision to stop smoking (module 1), strengthen this (module 2), to reiterate the decision to quit and provide encouragement through the cessation process (module 3 ).

AC7-Nicotine Replacement Therapy (NRT): to facilitate the use of NRT, improve knowledge about them.

AC8-Social support: to use friends' videos as a way to gain the support of the smoker's entourage.

AC9-Craving: to obtain ideas of occupations, through videos, to manage craving; to play games, to receive practical advice and information about stress management techniques, use of NRTs and so on.

AC10-Progress and benefits: to track progress in smoking cessation and visualise it since the beginning.

AC11-Stress management: to provide various stress and emotion management techniques

AC12-Question and answer: to send questions to a smoking cessation specialist at the TIS platform.

AC13-Telephone directory: to find a smoking cessation specialist.

AC14-Click to call: to call a smoking cessation specialist at the TIS platform

AC15-Weight management: tips on weight management.

AC16-Quit checklist: once the quit date has been set, the smoker receives advice to make a plan to quit. $\mathrm{He} / \mathrm{she}$ can refer to it and check off the tasks completed.

There is also a set of email or push-app text messages/notifications (roughly 170) with various purposes: welcome messages for each module; messages promoting activities and questionnaires, reminders and follow-up messages, unidirectional messages (personalised or not) to provide advice and encouragement to use the application; personalised messages relating to the answers at the different questionnaires; messages about the quitting date.

In addition, all contacts are tailored to the answers from the eight position questionnaires in the application, and on the smoker's progress through the four of the application's modules:
- Module 1-Participants are not yet ready to quit smoking (they have yet to set a quit date). This module is intended to increase the participants' resolve/resoluteness/resolution to quit and help them set a stopping date. Participants only leave this module once they have set a quitting date. Tailoring: text messaging is not intense at this stage and activities mainly designed to enhance motivation, report pros and cons, reach a balanced decision and so on.

- Module 2-Participants are ready to quit (they have set a date). This module aims to provide the best possible conditions to help participants prepare in the run-up to their quitting date. Participants leave this module on the morning of their quitting date unless they choose to cancel, in which case they return to module 1. Tailoring: text messaging will be intensive the day before the quit date and activities are mainly aimed at providing social support, pharmacological support, at setting challenges and so on.

- Module 3: Participants have stopped smoking. In this module they are given support and advice in detecting and avoiding possible relapses. Tailoring: text messaging will be highly intense. Activities are focused on reassurance, social comparison, social support and information about relapses and so on.

- Module 4-Participants have relapsed. This is a shortterm module whose purpose is to help willing participants to manage their relapse and return to either module 1, 2 or 3 . They can leave module 4 once they have completed a questionnaire designed to ascertain which module they should reintegrate. Tailoring: activities and text messaging aim to reassure and remotivate the smoker.

Participants start with the module adapted to their stage with regard to tobacco consumption (ie, module 1 : participants are not yet ready to quit smoking; module 2: participants are ready to quit; module 3: participants have stopped smoking; module 4: participants have relapsed.)

This process is presented in table 1.

\section{Control arm}

Participants assigned to the control arm are exposed to an information page which lists smoking cessation resources readily available in France and recommended by HAS. $^{32}$ This is the common practice pathway. Participants are given a link to access the page and there are four tabs:

- The effects of smoking: this section provides information about how tobacco affects morbidity, mortality and quality of life.

- The benefits of a smoke-free life: this section provides information about the short, medium and long-term benefits of smoking cessation and how quality of life is likely to improve.

- Your current situation: this section involves conducting a small survey about the participants' smoking 
Table 1 e-TIS support process

\begin{tabular}{|c|c|c|c|c|}
\hline & $\begin{array}{l}\text { Module } 1 \\
\text { Contemplation } \\
\text { I am thinking of quitting }\end{array}$ & $\begin{array}{l}\text { Module } 2 \\
\text { Preparation } \\
\text { I am ready to quit }\end{array}$ & $\begin{array}{l}\text { Module } 3 \\
\text { Quitting } \\
\text { I am quitting }\end{array}$ & $\begin{array}{l}\text { Module } 4 \\
\text { Relapse } \\
\text { I have slipped }\end{array}$ \\
\hline Context & $\begin{array}{l}\text { Smokers who are } \\
\text { contemplating but who } \\
\text { have yet to set a quit date }\end{array}$ & $\begin{array}{l}\text { Smokers preparing for the } \\
\text { quit date they have set }\end{array}$ & Smokers who have quit & $\begin{array}{l}\text { Smokers who } \\
\text { relapse }\end{array}$ \\
\hline Objectives & $\begin{array}{l}\text { Help smokers increase } \\
\text { their resolve } \\
\text { Help smokers set a quit } \\
\text { date }\end{array}$ & $\begin{array}{l}\text { Help smokers prepare in } \\
\text { the run-up to their quit date } \\
\text { in the best possible } \\
\text { conditions }\end{array}$ & $\begin{array}{l}\text { Provide support and } \\
\text { advice in detecting and } \\
\text { avoiding possible lapses/ } \\
\text { relapses }\end{array}$ & $\begin{array}{l}\text { Help willing users } \\
\text { return to modules } \\
1,2 \text { or } 3 \\
\text { Provide individual } \\
\text { support }\end{array}$ \\
\hline $\begin{array}{l}\text { Level of contact } \\
\text { throughout the } \\
\text { intervention }\end{array}$ & $\begin{array}{l}\text { Low intensity } \\
3-4 \text { messages per week }\end{array}$ & $\begin{array}{l}\text { Intense } \\
\text { one message per day } \\
\text { One day before the quit } \\
\text { date, messaging will be } \\
\text { intense ( } 3-4 \text { messages) }\end{array}$ & $\begin{array}{l}\text { Up to } D+7 \\
\text { Highly intense } \\
2-4 \text { messages per day } \\
\text { Between } D+8 \text { and } D+28 \text {; } \\
D+29 \text { and } D+56 ; D+57 \\
\text { and } D+180 \\
\text { Intensity declines }\end{array}$ & $\mathrm{N} / \mathrm{A}$ \\
\hline
\end{tabular}

habits to assess their levels of consumption, dependency and motivation to quit.

- How to quit smoking: this section informs smokers about the various cessation methods recommended by HAS and how to apply for them.

\section{Primary outcome}

For the main analysis, the primary end point is minimum 7 -day point abstinence at 6 months. To define the 6 -month follow-up, we follow the recommendations of the Cochrane review on internet-based intervention and mobile interventions ${ }^{11}{ }^{12}$ and of the European Medicines Agency. ${ }^{33}$ Point prevalence abstinence (PPA) is considered the most appropriate measure for intervention evaluation studies. ${ }^{34}$ The National Interagency Council on Smoking and Health recommends PPA for a minimum 24 hours at 3 months, 7-day abstinence at 6 months and 30 days at 12 months. ${ }^{35}$ Biochemical validation will not be used; for most situations, and particularly in community-based interventions (vs clinical interventions) and with an adult population, ${ }^{35}$ the misreporting rates are relatively low, typically near zero and seldom exceeding $5 \%$. In such settings biochemical validation of the study is not necessary given its cost and its lack of acceptance. ${ }^{35}$

\section{Secondary outcomes}

Following the same references, ${ }^{11} 123334$ we have defined the secondary endpoints for the main analysis:

- continuous abstinence at 6 months

- continuous abstinence at 12 months

- minimum 24-hour point abstinence at 3 months

- minimum 30-day point abstinence at 12 months

- number and duration of quit attempts

- progress through the four modules in the intervention (module changes and length of stay in each).

\section{Other data}

Other data will be collected in order to characterise consumption, dependency, determinants of abstinence and the process. This will allow us to explain the results obtained and to achieve our secondary objectives. Table 2 sets out these data:

\section{Data collection}

\section{Primary and secondary outcomes collection}

The measures in both arms will be internet-based. Data will be collected via self-reporting questionnaires at set times ( $\mathrm{T}+3,6$ and 12 months).

\section{Other data collection}

The measures in both arms will be internet-based except for data relating to e-TIS components which only concerns the intervention arm (E).

Data will be collected from four sources: an inclusion questionnaire (technical variables), an initial selfreporting questionnaire at T0, three follow-up selfreporting questionnaires ( $\mathrm{T}+3,6$ and 12 months) and routine collection via the internet platform of e-TIS. In the T0 questionnaire, the data collected will be differentiated according to the entry point into the intervention (1-4). In the follow-up questionnaire, the data collected will be differentiated according the participant's status: has stopped smoking or not. Table 3 describes how each measure will be recorded.

At each follow-up point, an email and text message will be sent twice as a reminder. Throughout the study, there will be routine and ongoing data collection via the system for the intervention arm only (E).

\section{Analysis plan}

The efficacy will be analysed using blind analysis by comparison at 3, 6, 12 months in both arms using the 
Table 2 Other variables

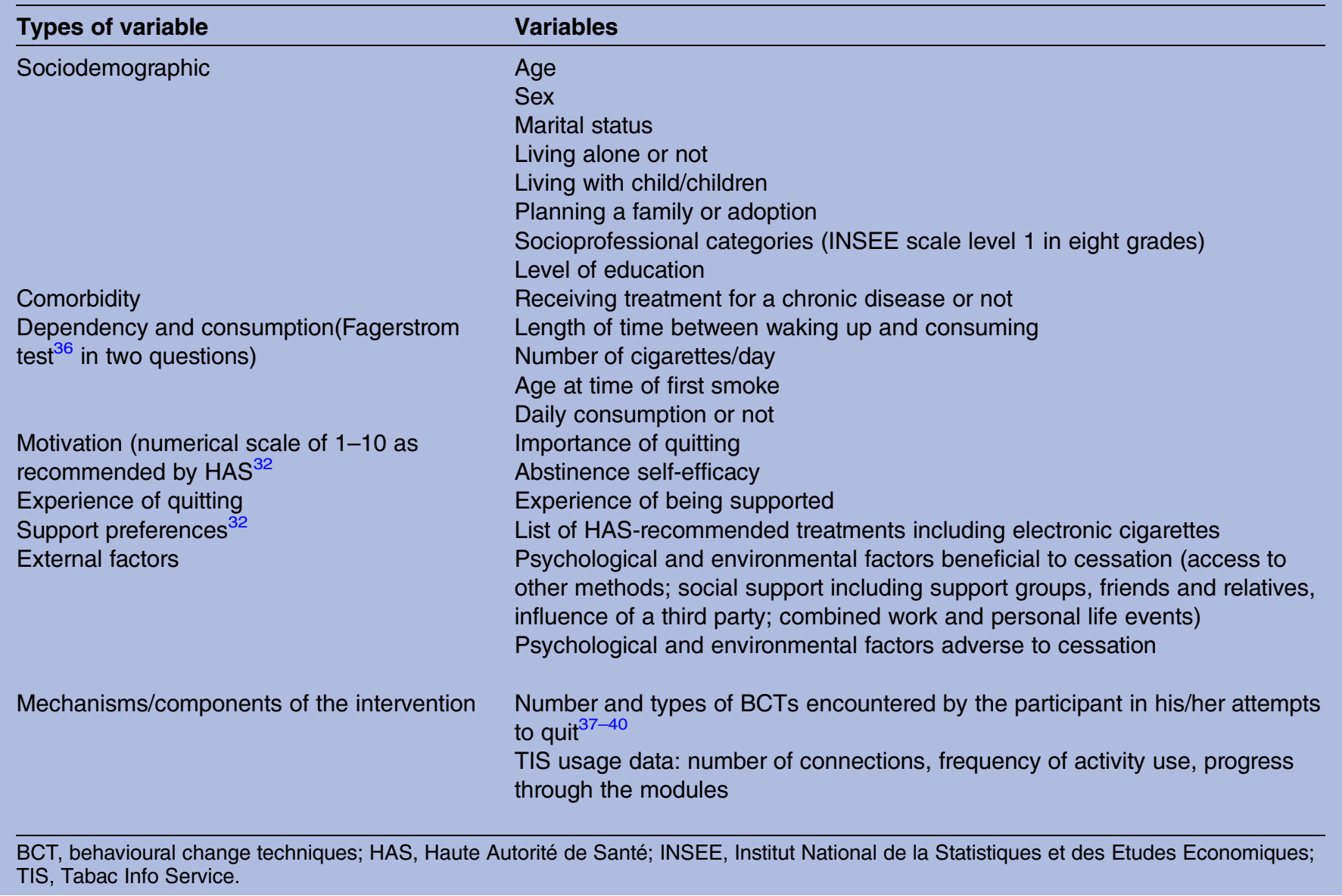

primary and secondary endpoints. In the main analysis, data will be analysed by intention to treat and then by per protocol analyses. For the main analysis, those participants lost to follow-up (those who don't answer the questionnaires) will be considered smokers as recommended. ${ }^{123341}$ For the secondary analysis, we will only consider those who will not be lost to follow-up. The efficacy analysis will be blinded to the randomisation group, but the processes and mechanisms by their nature will be analysed openly. The proportion of quitters in each arm will be estimated, as well as an OR and its 95\% CI by logistic univariate regression. We will also conduct an analysis on efficacy in subgroups using the following predefined variables: socioprofessional classification, sex, age, point of entry onto the intervention. Multiple imputation methodologies will be used to limit the amount of possible missing data.

To assess the processes, we will clarify the intervention components (the BCTs used in e-TIS) and the environmental components (beneficial and adverse factors for cessation) to which the subjects have been exposed. We will also look into how e-TIS has been used (frequency and duration of use, the activities performed). To conduct this analysis, we will proceed in three stages:
Stage 1: characterise the intervention theory

This involves attributing one or several BCTs to each contact, such as a message, an activity and a questionnaire, between the user and the e-TIS intervention, which will establish the generic intervention theory of the said intervention (components). ${ }^{42}{ }^{43}$ This will be carried out by a multidisciplinary committee. It will take three iterative steps: (1) two groups of researchers will attribute BCTs to contacts, (2) both groups will compare their results and draw a consensus and (3) researchers will present their results to the committee which will in turn draw a consensus. All components of e-TIS will be identified as universal BCTs of the taxonomy.

Each user will go through the intervention in his/her own way and this intervention theory will come across differently according to a combination of contextual factors including the pathway taken and the use of the website. This all leads to different intervention doses (number and type of BCTs to which the user is exposed) and to different response doses (module changes, end of platform use, smoking cessation, relapse and so on). ${ }^{44}$

\section{Stage 2: describe the pathway of users in the intervention arm}

In this stage we will describe the user pathways within the e-TIS intervention, looking at the combinations of 
Table 3 Recording procedures

\begin{tabular}{|c|c|c|c|c|}
\hline $\begin{array}{l}\text { Types of } \\
\text { measures }\end{array}$ & $\begin{array}{l}\text { Inclusion questionnaire } \\
\text { (associated with the } \\
\text { consent form) }\end{array}$ & Questionnaire T0 & $\begin{array}{l}\text { Questionnaire T3, } \\
\text { T6, T12 }\end{array}$ & $\begin{array}{l}\text { Extracted from the } \\
\text { application (position } \\
\text { questionnaires or uses of } \\
\text { the e-TIS components) }\end{array}$ \\
\hline $\begin{array}{l}\text { Primary } \\
\text { outcomes }\end{array}$ & & & $\begin{array}{l}\text { Minimum 7-day } \\
\text { point abstinence } \\
\text { at } 6 \text { months }\end{array}$ & \\
\hline $\begin{array}{l}\text { Secondary } \\
\text { outcomes }\end{array}$ & & & $\begin{array}{l}\text { Continuous } \\
\text { abstinence at } \\
6 \text { month } \\
\text { Continuous } \\
\text { abstinence at } \\
12 \text { month } \\
\text { Minimum 24-hour } \\
\text { point abstinence } \\
\text { at } 3 \text { months } \\
\text { Minimum 30-day } \\
\text { point abstinence } \\
\text { at } 12 \text { months } \\
\text { Number and } \\
\text { duration of quit } \\
\text { attempts }\end{array}$ & $\begin{array}{l}\text { Progress through the } \\
\text { four modules in the } \\
\text { intervention }\end{array}$ \\
\hline $\begin{array}{l}\text { Others } \\
\text { variables }\end{array}$ & $\begin{array}{l}\text { Technical variables } \\
\text { (email, phone number, } \\
\text { date of entry) } \\
\text { Sociodemographic: sex }\end{array}$ & $\begin{array}{l}\text { Sociodemographic } \\
\text { variables excepted } \\
\text { sex } \\
\text { Dependency and } \\
\text { consumptions } \\
\text { variables } \\
\text { Motivation variables } \\
\text { Specifically for control } \\
\text { group: } \\
\text { Comorbidity variables } \\
\text { Experience of quitting } \\
\text { Support preferences }\end{array}$ & $\begin{array}{l}\text { Dependency and } \\
\text { consumptions } \\
\text { variables } \\
\text { Motivation } \\
\text { variables } \\
\text { Added support } \\
\text { using } \\
\text { External factors }\end{array}$ & $\begin{array}{l}\text { Specifically for intervention } \\
\text { group: } \\
\text { Comorbidity variables } \\
\text { Experience of quitting } \\
\text { Support preferences } \\
\text { Mechanisms/ } \\
\text { components of the } \\
\text { intervention }\end{array}$ \\
\hline
\end{tabular}

BCTs to which users are exposed (number, type, associations), the types of environmental and social factors encountered (social support, substitutes, life events and so on) and the use of the e-TIS platform. From this we will be able to identify the most common pathway used through the intervention. To identify cluster of participants following similar pathway we will use the SAS Proc Traj. ${ }^{45}$ This procedure is a specialised application of finite mixture modelling designed to identify clusters of individuals following similar progressions of an outcome over time (or trajectory). Outcome variable will be smoking status (ie, abstinence, quit attempts); timevarying dependent covariables will be BCTs used, progress through the modules and other factors measured during follow-up.

\section{Stage 3: analyse the influence of user characteristics,} processes, context and exposure to BCTs on the outcome The clusters developed stage 2 will be used as dependent variables in a model designed to analyse the influence of users' characteristics (eg, sociodemographic, dependency, motivation, quit attempts or experiences, added support, contextual factors) on the trajectory. For that we will use a multivariate, multilevel (ie, participants, entry module and identified pathway) statistical analysis using the SAS Proc Mixed. ${ }^{46}$ The purpose of this analysis is to clarify how the generic theory best applies to the different users going through the intervention. It will therefore enable us to assess the mechanisms and conditions of the theory's efficacy, in relation to options for the degree of intervention, exposure to context and to the different dose responses.

\section{Ethical considerations and dissemination}

Participants must give their informed consent to participate in the study. They will be informed that they can refuse and drop out at any time. Subjects in the control arm will be asked to register to the e-TIS website once they have been deemed suitable for treatment via an initial evaluation. The data collected and processed in this study will be performed so in compliance with the Act of 6 January 1978 on Data Processing, Data Files and 
Individual Liberties, as amended by the Act 2014-801 of 6 August 2004. The CNAMTS has a compliance undertaking with the Commission Nationale Informatique et Libertés (CNIL) (national body for data protection) as set out by Decree no. 2012-1249 of 9 November 2012 in the Conseil d'Etat (Council of State) which authorises public health insurance funds (CNAMTS) to implement healthcare prevention and support programmes for their beneficiaries.

The study protocol was reviewed by the ethical and deontological institutional review board of the Institut National de Veille Sanitaire (INVS) on 18 April 2016. All the proposals and recommendations put forward by the ethics committee have been followed and integrated into the amended version of the protocol.

\section{DISCUSSION}

Behavioural change interventions are complex, with outcomes depending as much on the intervention itself as on participant characteristics and the context of intervention delivery. ${ }^{23} 26{ }^{47}$ In the case, this variability is borne out in the literature-the demonstrated effects are very heterogeneous due to the influence of the population characteristics, the way the intervention is used by participants, and the context in which it is used. This is further compounded by the fact that the intervention is dematerialised and that each participant has a unique experience of it.

In view of the above, participant compliance should be improved and the support provided within the intervention should be fully tailored to the circumstances of each participants. For this to happen, we will need to work on two levels: intervention design and evaluation design. Consequently the intervention has been based on data from literature and from the most used theoretical models used for helping people to quit. We have developed an evaluation protocol that no only allows us to conduct a thorough assessment of the intervention's efficacy via the Randomized Control Trial (RCT) and seeks to clarify the conditions of its efficacy. These conditions relate to the participants; the different components of the TIS used by the participants; the psychological, social and environmental factors possibly affecting the participants during the study. To guide us, we use the references currently in use for evaluating complex interventions.

In this respect we hope both to contribute to better demonstrating the efficacy of online and mobile phone interventions, and to influence prevention strategies through an understanding of compliance and change phenomena.

\footnotetext{
Author affiliations

${ }^{1}$ Chaire de Recherche en prévention des cancers, UMR 6051 (CRAPE), EHESP, Paris, France

${ }^{2}$ EA 4360, APEMAC, Université de Lorraine, Nancy, France

${ }^{3}$ CNAMTS, Paris, France

${ }^{4}$ Centre Addiction, Hôpital Européen Georges Pompidou, Pôle PsychiatrieAddictologie, Hôpitaux Universitaires Paris-Ouest, Paris, France
}

${ }^{5}$ Société Francophone de Tabacologie, Ollainville, France

${ }^{6}$ Santé Publique France, Saint maurice, France

${ }^{7}$ Université Paris VI CHU Pitié-Salpêtrière, Paris, France

${ }^{8}$ APHP, Institut de cardiologie, Hopital de la Pitié-Salpêtrière, Paris, France

Acknowledgements The authors wish to thank Jocelyn Courtois (CNAMTS), Eliane Albuisson, Marc Borie, Geoffroy Cagninacci (CHU de Nancy) and Viêt Nguyen-Thanh (Santé Publique France).

Contributors $L C$ and FA deal with the scientific coordination of the whole study; PB, IV, AP, Anne Laurence Le Faou ( ALLF), BL, TD and PA designed the e-TIS intervention; LC prepared the first draft; all authors reviewed and contributed to the article.

Funding This study is funded by the CNAMTS for the period 2016-2018.

Competing interests ALF reports grants from Pfizer, non-financial support from J\&J, outside the submitted work; DT reports personal fees from Pfizer, personal fees from Novartis, personal fees from Pierre Fabre Santé, outside the submitted work.

Provenance and peer review Not commissioned; externally peer reviewed.

Open Access This is an Open Access article distributed in accordance with the Creative Commons Attribution Non Commercial (CC BY-NC 4.0) license, which permits others to distribute, remix, adapt, build upon this work noncommercially, and license their derivative works on different terms, provided the original work is properly cited and the use is non-commercial. See: http:// creativecommons.org/licenses/by-nc/4.0/

\section{REFERENCES}

1. Vos T, Barber RM, Bell B, et al. Global, regional, and national incidence, prevalence, and years lived with disability for 301 acute and chronic diseases and injuries in 188 countries, 1990-2013: a systematic analysis for the Global Burden of Disease Study 2013. Lancet 2015;386:743-800.

2. Licaj I, Clavel-Chapelon F, Boutron-Ruault M, et al. Impact du tabac sur la mortalité totale et sur la mortalité par cause dans l'étude européenne EPIC (European prospective investigation into cancerand nutrition). BEH N²0/21. 2013;234

3. Pirie K, Peto R, Reeves GK, et al., Million Women Study Collaborators. The 21st century hazards of smoking and benefits of stopping: a prospective study of one million women in the UK. Lancet Lond Engl 2013;381:133-41.

4. Doll R, Peto R, Boreham J, et al. Mortality in relation to smoking: 50 years' observations on male British doctors. BMJ 2004;328:1519.

5. Peto R, Darby S, Deo H, et al. Smoking, smoking cessation, and lung cancer in the UK since 1950: combination of national statistics with two case-control studies. BMJ 2000:321:323-9.

6. Lancaster T, Stead LF. Individual behavioural counselling for smoking cessation. Cochrane Database Syst Rev 2005;(2): CD001292.

7. Lai DT, Cahill K, Qin Y, et al. Motivational interviewing for smoking cessation. Cochrane Database Syst Rev 2010(1):CD006936.

8. Stead LF, Hartmann-Boyce J, Perera R, et al. Telephone counselling for smoking cessation. Cochrane Database Syst Rev 2013;(8):CD002850.

9. Rice VH, Hartmann-Boyce J, Stead LF. Nursing interventions for smoking cessation. Cochrane Database Syst Rev. 2013;(8): CD001188.

10. Lancaster T, Stead LF. Self-help interventions for smoking cessation. Cochrane Database Syst Rev 2005;(3):CD001118.

11. Whittaker R, McRobbie H, Bullen C, et al. Mobile phone-based interventions for smoking cessation. Cochrane Database Syst Rev 2016;4:CD006611.

12. Civljak M, Stead LF, Hartmann-Boyce J, et al. Internet-based interventions for smoking cessation. Cochrane Database Syst Rev 2013I;(7):CD007078.

13. Prochaska JO, DiClemente CC. Stages of change in the modification of problem behaviors. Prog Behav Modif 1992;28:183-218.

14. Bandura A. Human agency in social cognitive theory. Am Psychol 1989;44:1175-84.

15. Miller WR, Rose GS. Toward a theory of motivational interviewing. Am Psychol 2009;64:527-37.

16. Miller WR, Rollnick S. Motivational interviewing: preparing people for change. Guilford Press, 2002:456.

17. Beauregard L, Dumont S. La mesure du soutien social. Serv Soc 1996;45:55. 
18. Moscovici S, Lagache D. La Psychanalyse: Son image et son public, étude sur la représentation sociale de la psychanalyse, par Serge Moscovici, Préface par le Dr Daniel Lagache. Presses universitaires de France Vendôme, Impr. des P.U.F.; 1961.

19. Janis IL, Mann L. Emergency decision making: a theoretical analysis of responses to disaster warnings. J Human Stress 1977;3:35-45.

20. Turner L, Shamseer L, Altman DG, et al. Consolidated standards of reporting trials (CONSORT) and the completeness of reporting of randomised controlled trials (RCTs) published in medical journals. Cochrane Database Syst Rev 2012;11:MR000030.

21. Chan A-W, Tetzlaff JM, Altman DG, et al. SPIRIT 2013 statement: defining standard protocol items for clinical trials. Ann Intern Med 2013;158:200-7.

22. Craig P, Dieppe $\mathrm{P}$, Macintyre $\mathrm{S}$, et al. Developing and evaluating complex interventions: the new medical research council guidance. BMJ 2008;337:a1655.

23. Moore GF, Audrey S, Barker M, et al. Process evaluation of complex interventions: Medical Research Council guidance. BMJ 2015;350: h1258.

24. Albrecht L, Archibald M, Arseneau D, et al. Development of a checklist to assess the quality of reporting of knowledge translation interventions using the Workgroup for Intervention Development and Evaluation Research (WIDER) recommendations. Implement Sci IS 2013;8:52.

25. Craig P, Dieppe P, Macintyre S, et al. Developing and evaluating complex interventions: new guidance: MRC, 2008

26. Hawe P, Shiell A, Riley T. Complex interventions: how "out of control" can a randomised controlled trial be? Br Med J Aust 2004;328:1561-3.

27. Michie S, Wood CE, Johnston M, et al. Behaviour change techniques: the development and evaluation of a taxonomic method for reporting and describing behaviour change interventions (a suite of five studies involving consensus methods, randomised controlled trials and analysis of qualitative data). Health Technol Assess 2015;19:1-188.

28. Michie S, Richardson M, Johnston $\mathrm{M}$, et al. The behavior change technique taxonomy (v1) of 93 hierarchically clustered techniques: building an international consensus for the reporting of behavior change interventions. Ann Behav Med 2013;46:81-95.

29. Brown J, Michie S, Geraghty AW, et al. Internet-based intervention for smoking cessation (StopAdvisor) in people with low and high socioeconomic status: a randomised controlled trial. Lancet Respir Med 2014:2:997-1006.

30. Dupont WD, Plummer WD. Power and sample size calculations. A review and computer program. Control Clin Trials 1990;11:116-28.

31. INPES—La collection "Évolutions" [Internet]. [cited 2016 Oct 29]. http://inpes.santepubliquefrance.fr/evolutions/default.asp

32. Recommandations_Arrêt de la consommation de tabac_octobre 2014-recommandations_-_arret_de_la_consommation_de_tabac_ octobre_2014_2014-11-17_14-13-23_985.pdf [Internet]. [cited 2016 Jun 3]. http://www.has-sante.fr/portail/upload/docs/application/pdf/ 2014-11/recommandations_-_arret_de_la_consommation_de_ tabac octobre 2014_2014-11-17_14-13-23 985.pdf

33. Guideline on Treatment of Smoking-WC500003509.pdf [Internet] [cited 2016 Oct 18]. http://www.ema.europa.eu/docs/en_GB/ document library/Scientific guideline/2009/09/WC500003509.pdf

34. Hughes JR, Keely JP, Niaura RS, et al. Measures of abstinence in clinical trials: issues and recommendations. Nicotine Tob Res Off J Soc Res Nicotine Tob 2003:5:13-25.

35. Velicer WF, Prochaska JO, Rossi JS, et al. Assessing outcome in smoking cessation studies. Psychol Bull 1992;111:23-41.

36. Fagerström K. Determinants of tobacco use and renaming the FTND to the Fagerstrom test for cigarette dependence. Nicotine Tob Res Off J Soc Res Nicotine Tob 2012:14:75-8.

37. Michie S, Hyder N, Walia A, et al. Development of a taxonomy of behaviour change techniques used in individual behavioural support for smoking cessation. Addict Behav 2011;36:315-19.

38. Michie S, Brown J, Geraghty AW, et al. Development of stop advisor: a theory-based interactive internet-based smoking cessation intervention. Transl Behav Med 2012;2:263-75.

39. Lorencatto F, West R, Christopherson C, et al. Assessing fidelity of delivery of smoking cessation behavioural support in practice. Implement Sci IS 2013;8:40.

40. Lorencatto F, West R, Seymour N, et al. Developing a method for specifying the components of behavior change interventions in practice: the example of smoking cessation. J Consult Clin Psychol 2013;81:528-44.

41. West $R$, Hajek $P$, Stead $L$, et al. Outcome criteria in smoking cessation trials: proposal for a common standard. Addict Abingdon Engl 2005;100:299-303.

42. MRC. A framework for development and evaluation of RCTs for complex interventions to improve health. Med Res Counc 2000

43. Pawson R, Greenhalgh T, Harvey G, et al. Realist review: a new method of systematic review designed for complex policy interventions. J Health Serv Res 2005;10:21-34.

44. Victora CG, Habicht JP, Bryce J. Evidence-based public health: moving beyond randomized trials. Am J Public Health 2004;94:400-5.

45. Jones BL, Nagin DS. Advances in group-based trajectory modeling and an SAS procedure for estimating them. Sociol Methods Res 2007;35:542-71.

46. Singer JD. Using SAS PROC MIXED to fit multilevel models, hierarchical models, and individual growth models. J Educ Behav Stat 1998;23:323.

47. Tarquinio C, Kivits J, Minary L, et al. Evaluating complex interventions: perspectives and issues for health behaviour change interventions. Psychol Health 2015;30:35-51. 